\title{
CORRESPONDENCE
}

Multiple Decrement Tables

The Joint Editors

I9 fanuary 1949

The fournal of the Institute of

Actuaries Students' Society

Sirs,

I have always understood that the primary purpose of our Fournal is to help the student in his studies. I feel I must therefore raise an objection to the tedious discussion of Karup's 'proof' that $(\alpha \mu)_{x}^{\alpha}=\mu_{x}^{\alpha}$, which has occupied space in four numbers of the fournal (Volume viI, nos. 2 and 3 and Volume viII, nos. I and 2). The last reference consists of seven pages of most laborious mathematics which is no credit to the illustrious name of its author, and is sheer waste of time for any student to read.

I must admit that the point discussed is important, but, I suggest, the reviewer and the authors of the book on Multiple Decrement Tables should have got together long before this, sorted the matter out and produced a simple statement for the student.

May I be permitted to discuss the problem in a straightforward manner for the benefit of those students who are studying Part III of the syllabus? The problem is simply this. Is the force of decrement $\alpha$ in a multiple decrement table necessarily equal to the force of decrement in a table where $\alpha$ is the only decrement? Since multiple and single decrement tables are simply models constructed to solve actuarial problems, we can always make this equality one of our assumptions, but this does not mean that tables so constructed will necessarily provide a reasonable model of what actually occurs. A simple example will illustrate this. Consider an actual investigation into the experience of a group of lives subject to three decrements (i) death, (ii) becoming engaged to be married, and (iii) becoming married. In such an investigation the marriage rates would be practically zero as nearly everyone becomes engaged before marriage. The force of marriage in a double decrement table 
(decrements engagement and marriage) based on this data would be very small. If the experience of the same group of lives were investigated with death and marriage as the only decrements normal marriage rates would be obtained and the force of marriage in a single decrement (marriage) table based on this experience would be very different from the force of marriage in the double decrement table referred to above.

Let us now turn to Karup's demonstration, and consider exactly what he proves. He considers two identical bodies of lives aged $x+t$ and shows that the force of decrement $\alpha$ at age $x+t$ is the same whether the lives are subject to the decrement $\alpha$ only or to two decrements $\alpha$ and $\beta$. (This fact can be demonstrated much more easily and is always true provided all forces of decrement are finite.) Karup does not prove, and it cannot be generally proved, that the same equality holds at any later time when the bodies of lives are no longer identical owing to the operation of the different decrements.

I advise Part III. students to waste no further time on this theorem of Karup's. In case anyone is tempted to work through the theorem line by line, however, I would warn him that the functions $d_{x}^{\beta}$ in the expression for $\mathrm{K}$ (formula (5)) are not, as the notation suggests, functions of a single decrement table where $\beta$ is the only decrement.

$$
\text { Yours faithfully, }
$$

L. H. LONGLEY-COOK

$\mathrm{I}_{42}$ Holborn Bars

London, E.C. I

\section{Valuations for Estate Duty}

The Joint Editors

26 Fanuary 1949

The fournal of the Institute of

Actuaries Students' Society

Sirs,

In the very interesting and informative notes on valuations for Estate Duty purposes Mr Goodchild refers on p. 83 of Part 2, Vol. viu of the fournal, to the basis of valuation in the case of joint annuities. 